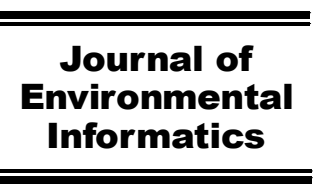

www.iseis.org/jei

\title{
Extension of the Hybrid Ant Colony Optimization Algorithm for Layout and Size Optimization of Sewer Networks
}

\author{
R. Moeini ${ }^{1 *}$ and M. H. Afshar ${ }^{2}$ \\ ${ }^{1}$ Department of Civil Engineering, Faculty of Civil Engineering and Transportation, University of Isfahan, Isfahan 81746-73441, Iran \\ ${ }^{2}$ School of Civil Engineering \& Enviro-hydroinformatic Center of Excellence, Iran University of Science and Technology, Tehran 16765-16, Iran
}

Received 18 October 2015; revised 18 April 2016; accepted 3 May 2016; published online 23 December 2017

\begin{abstract}
In this paper, the incremental solution building capability of Ant Colony Optimization Algorithm (ACOA) is exploited using a Tree Growing Algorithm (TGA) augmented with the efficiency of Nonlinear Programming (NLP) methods leading to a hybrid ACOA-TGA-NLP algorithm for the effective layout and pipe size optimization of pumped/gravitational sewer networks. Solution of layout and pipe size optimization of sewer network requires the determination of pipe locations, pipe diameters, average pipe cover depths, drop and pump heights minimizing the total cost of the sewer network subject to operational constraints. The resulting problem is a highly constrained Mixed-Integer Nonlinear Programming (MINLP) problem presenting a challenge even to the modern heuristic search methods. In the proposed method, the TGA is used to construct feasible tree-like layouts out of the base layout defined for the sewer network, the ACOA is used to optimally determine the pipe diameters of the constructed layout, and finally NLP is used to determine the pipe slopes from which the remaining characteristics of the network such as pump/drop locations and heights are determined. In the NLP stage of the model, the velocity and flow depth constraints are expressed in terms of the slope constraints which are easily enforced as box constraint of the NLP solver leading to a considerable reduction of the search space size. The proposed hybrid ACOA-TGA-NLP has two significant advantages over other available methods. First, this method can be used for both pumped and gravitational sewer networks. Second, the computational effort is significantly reduced compared to alternative methods. Another method is also proposed here in which the layout of the network is determined by an ad-hoc method based on engineering judgment while the component design of the network is carried out by ACOA-NLP method as defined above. Proposed hybrid methods are used to solve a benchmark example from the literature and a hypothetical test example and the results are presented and compared with those produced by the existing methods such as SPST-DDDP, SDM-DDDP and GA-DDDP. The results indicate the efficiency and effectiveness of the proposed methods and in particular the ACOA-TGA-NLP method. In fact, the optimal solution of ACOA-TGA-NLP is 149, 64.1, 22.2 and $13.6 \%$ cheaper than those of ACOA-NLP, SPST-DDDP, SDM-DDDP and GA-DDDP methods, respectively, for the benchmark text example. Furthermore, ACOA-TGA-NLP yields a solution $80 \%$ cheaper than that of ACOA-NLP method for hypothetical test example.
\end{abstract}

Keywords: Ant Colony Optimization Algorithm, Tree Growing Algorithm, Nonlinear Programming, sewer network, layout and sizing

\section{Introduction}

Due to expansion of urbanization, sewer network has become an essential infrastructure for everyday life in developed urban areas. Urban areas without an effective sewer network may encounter many problems such as public health threats and environmental damages. High costs associated with sewer network have shown to be one of the main limiting factors in constructing sewer network. A relatively small change in the location and size of sewer network components, may lead to a huge cost saving. Having a suitable and costeffective sewer network is normally interpreted as finding the

${ }^{*}$ Corresponding author. Tel.: 0098-31-37935293; fax: 0098-31-37935231.
E-mail address: r.moeini@eng.ui.ac.ir (R. Moeini).

ISSN: 1726-2135 print/1684-8799 online

(C) 2019 ISEIS All rights reserved. doi: 10.3808/jei.201700369 solution for sewer network design optimization problem that minimizes infrastructural cost without violating operational requirements. The cost of a sewer system can be significantly reduced if the system configuration (layout), pipe diameters and pipe slopes can be effectively optimized.

There are many factors that influence the total costs of sewer network making it difficult for any engineer to identify the best economic alternative without using optimization techniques. Considerable researches have focused on developing useful optimization techniques for optimal design of sewer network in recent years. A general sewer network design optimization problem includes two sub-problems of 1) designing optimal layout (location) and 2) optimal sizing of network components. These sub-problems are strongly coupled and, therefore, can not be solved separately if an optimal solution to the whole problem is required. Due to the complex nature of the problem, however, most of the research in this field is carried out on either layout determination or component siz- 
ing. Haestad (2004) and Guo et al. (2008) reviewed a significant amount of research works in the field of sewer network design developed in the last 40 years.

Most of the works on the optimal design of sewer network are, therefore, restricted to the optimal component sizing using different methods. For example, the methods such as enumeration and heuristic approaches (Desher and Davis, 1986; Miles and Heaney, 1988; Charalambous and Elimam, 1990), Linear Programming (Dajani and Hasit, 1974; Elimam et al., 1989; Swamee and Sharma, 2013), Nonlinear Programming (Price, 1978; Swamee, 2001), Dynamic Programming (Walsh and Brown, 1973, Templeman and Walters, 1979; Gupta et al., 1983; Yen et al., 1984; Kulkarni and Khanna, 1985; Botrous et al., 2000) and Evolutionary Algorithms (EAs) such as Genetic Algorithm (Heaney et al., 1999; Liang et al. 2004, Afshar et al., 2006; Haghighi and Bakhshipour, 2012), Ant Colony Optimization Algorithm (Afshar, 2007; Afshar, 2010), Particle swarm optimization (Izquierdo et al., 2008), Simulated Annealing (Karovic and Mays, 2014) and Cellular Automata (Guo, 2005; Guo et al., 2007b; Afshar et al., 2011) have been proposed for optimal sizing of sewer network.

Nowadays, a new class of methods commonly named as hybrid methods have been proposed as a remedy to the shortcomings of both conventional and modern heuristic search methods for optimal design of sewer network. Hybrid methods are often designed as a combination of different conventional and heuristic optimization methods to overcome the limitations of using each of them alone. The main motivation for the hybridization of different optimization methods has been to obtain more efficient and effective methods. In fact, choosing a proper combination of different optimization methods is often the key for achieving top performance in solving any complex optimization problem.

Different hybrid methods have been proposed for optimal design of sewer network. For example, a hybrid model by combining Genetic Algorithm (GA) and Cellular Automata (Guo et al., 2006), a hybrid model by combining Cellular Automata (CA) with a Non-dominated Sorting Genetic Algorithm named NSGAII (Guo et al., 2007a), a hybrid model employing GA with a Quadratic Programming (QP) (Pan and Kao, 2009) and a hybrid method using Ant Colony Optimization Algorithm (ACOA) with Nonlinear Programming (NLP) method (Moeini, 2013) have been proposed for optimal component sizing of sewer networks with fixed layout.

While the literature is relatively rich regarding optimal component sizing of sewer network, only a few researchers have addressed the problem of layout determination and in particular the joint layout and size optimization of sewer network using different methods. Dynamic Programming (Argaman et al., 1973; Mays and Wenzel, 1976; Walters, 1985) was the first method for joint layout and component size optimization problem. Other methods such as Discrete Differential Dynamic Programming (DDDP) (Jang, 2006), Enumeration (Diogo and Graveto, 2006) and Simulated Annealing (Diogo and Graveto, 2006) have also been used for the joint layout and size optimization of sewer network. The use of hybrid methods for optimal layout and component size determination is, however, of recent origin. Li and Matthew (1990) was the first to propose a hybrid method for the problem by using a Searching Direction Method (SDM) for the layout determination and a DDDP for the optimal component sizing of the given layout. More recently, a hybrid method combining Ant Colony Optimization Algorithm (ACOA) with the Tree Growing Algorithm (TGA) was proposed with the pipe diameters as the decision variable of the problem (Moeini and Afshar, 2012). The method was later modified by changing the decision variables from diameter to nodal elevation allowing for the explicit satisfaction of slope constraints leading to more efficient and effective method (Moeini and Afshar, 2013). Both of these methods, however, were proposed for gravitational networks and could not consider any pump and drop in the final design. Haghighi (2013) proposed a hybrid method for the problem by using a GA for the layout determination and a DDDP for the optimal component sizing of the determined layout. Later, a hybrid method combining loop-by-loop cutting algorithm for the layout determination and Tabu search (TS) for the optimal component sizing had been proposed by Haghighi and Bakhshipour (2015) to solve this problem. Finally, Moeini and Afshar (2017b) proposed the Arc Based Ant Colony Optimization Algorithm (ABACOA) coupled with TGA for optimal design a gravitational sewer network in which the pipe diameters were taken as the decision variables of the problem.

In this paper, the ACOA-TGA, the Ant Colony Optimization Algorithm (ACOA) equipped with a Tree Growing Algorithm (TGA) of the Moeini and Afshar (2012) is hybridized with Nonlinear Programming (NLP) method for effective and efficient solution of the pumped/gravitational sewer networks layout and size optimization problem. In the proposed ACOATGA-NLP method, the TGA is used to construct feasible treelike layouts out of the base layout defined for the sewer network and the ACOA is used to optimally determine the pipe diameters of the constructed layout as the discrete decision variables of the problem, while the remaining part of the network design problem, namely pipe slopes determinations, is handled by an NLP method using predefined pipe diameters and sewer network layout. In the NLP method, the velocity and flow depth constraints are expressed in terms of the slope constraints which are then easily enforced as box constraint leading to a considerable reduction of computational effort. Once the sewer network layout, pipe diameters and slopes are determined for a trial solution, the assumption of minimum cover depth at the inlets of the sewer network is used to calculate the sewer pipe's nodal cover depths from which the pump and drop locations and heights at the network nodes are easily determined. This capability distinguishes this work from earlier ones which could only be used for gravitational network without any pump and drop. In summary, the proposed hybrid ACOA-TGA-NLP method has two significant advantages over the other available methods. First, this method can be used for both pumped and gravitational sewer networks. Second, the computational effort required by the method is significantly lower than that of available methods. 
Advantages of the method are highlighted when solving the test examples. The proposed method is used to solve a benchmark test example and a hypothetical test example and the results are presented and compared with the existing results and those produced by another hybrid method in which the layout is determined using an ad-hoc engineering based mechanism while the ACOA-NLP method of Moeini (2013) is used for component design. The results indicate the efficiency and effectiveness of the proposed methods and in particular the ACOA-TGA-NLP to optimally solve the problem of layout and size determination of sewer network.

\section{Sewer Network Design Optimization Problem}

A sewer network consists of pipes, manholes, drops, pumping stations and other appurtenances as needed. Sewer network is designed to collect and transport sewer from house to wastewater treatment plants. Design of a sewer network consists of generating an adapted sewer network layout and performing hydraulic design to find pipe sizes, excavation depths, pump/drop locations and heights, and other hydraulic and design parameters for the specific layout. Finding the optimal layout and carrying out the hydraulic design of sewer network are quite complex tasks which can only be performed using optimization methods considering the vast number of alternatives for the location of the pipes, their sizes and slopes and other components of the network such as pump and drops. The problem of sewer network design may be divided into two phases: (1) selection of optimal layout, (2) optimal sizing of the network components. Determination of sewer network layout is of great importance because it serves as the foundation of the hydraulic design and, therefore, influences the final cost of the network.

The problem of joint layout and component size determinations of a sewer network can be mathematically defined as determining the pipe connections, pumping station locations, pumping and drop heights, pipe diameters and average cover depth of the pipes such that the network cost is minimized while observing the operational and constructional constraints. Generally, the network cost consists of construction, maintenance and operation cost as follows:

Minimize $C=C_{\text {con }}+C_{\text {main }}+C_{o p r}$

where $C=$ total cost of the sewer network; $C_{c o n}=$ construction cost of the sewer network which is a function of the network layout, sewer pipe sizes, pump and drop heights and locations, pump discharges, sewer pipe slopes, and average pipe cover depths of the network; $C_{\text {main }}=$ maintenance cost of the sewer network; and $C_{o p r}=$ operation cost of the sewer network which is mainly a function of the pumping heights and discharges.

This problem is subjected to topological, hydraulic, and availability constraints. Topological constraint requires that the network has a branched layout configuration. In addition, a sewer network should observe the hydraulic constraints such as minimum and maximum sewer pipes cover depths, maximum and minimum sewer flow velocities, minimum sewer pipe slopes, minimum and maximum relative flow depths, progressive pipe diameters, partially-full pipe flow condition, and the availability constraint defined by the requirement that the pipe diameters should be selected from a set of commercially available pipe diameters. These constraints can be mathematically defined as (Moeini and Afshar, 2012 \& 2013):

$$
\begin{aligned}
& X_{i j}+X_{j i}=1 \quad \forall l=1, \ldots, N \\
& \sum_{j=1}^{N_{i}} X_{i j}=1 \quad \forall i=1, \ldots, K \\
& \sum_{j=1}^{N_{i}} X_{j i} Q_{l}-\sum_{j=1}^{N_{i}} X_{i j}\left(Q_{l}+q_{l}\right)=0 \quad \forall i=1, \ldots, K \\
& E_{\text {min }} \leq E_{l} \leq E_{\max } \quad \forall l=1, \ldots, N \\
& V_{\text {min }} \leq V_{l} \leq V_{\max } \quad \forall l=1, \ldots, N \\
& S_{l} \geq S_{\min } \quad \forall l=1, \ldots, N \\
& \beta_{\min } \leq\left(\frac{y}{d}\right)_{l} \leq \beta_{\max } \quad \forall l=1, \ldots, N \\
& Q_{l}=\frac{1}{n} A_{l} R_{l}^{\frac{2}{3}} S_{l}^{\frac{1}{2}} \quad \forall l=1, \ldots, N \\
& d_{l} \leq \overrightarrow{\boldsymbol{d}}_{l} \quad \forall l=1, \ldots, N \\
& d_{l} \in \boldsymbol{D} \quad \forall l=1, \ldots, N
\end{aligned}
$$

where $X_{i j}=$ a binary variable with a value of 1 for pipe $l$ with a flow direction from node $i$ to node $j$ and zero otherwise; $N_{i}=$ the number of pipe connected to node $i, K=$ the total number of nodes, $Q_{l}=$ the discharge of pipe $l$ considered between nodes $i$ and $j, q_{l}=$ the local discharge of pipe $l, E_{\min }=$ minimum cover depth of sewer pipe; $E_{\max }=$ maximum cover depth of sewer pipe; $E_{l}=$ average cover depth of sewer pipe $l ; N=$ total number of network pipes, $V_{l}=$ flow velocity of pipe $l$; $V_{\max }=$ maximum allowable sewer flow velocity; $V_{\text {min }}=$ minimum allowable sewer flow velocity; $S_{l}=$ slope of the sewer pipe $l ; S_{\min }=$ minimum sewer pipe slope; $d_{l}=$ diameter of sewer pipe $l ; y_{l}=$ sewer flow depth in pipe $l ; \beta_{\max }=$ maximum allowable relative flow depth; $\beta_{\min }=$ minimum allowable relative flow depth; $\boldsymbol{D}=$ discrete set of commercially available pipe diameters; $A_{l}=$ wetted cross sectional area of sewer pipe $l$ at flow depth of $y_{l} ; R_{l}=$ hydraulic radius of the sewer pipe $l$ at flow depth of $y_{l} ; n=$ Manning constant; and $\vec{d}_{l}=$ set of downstream pipe diameters of pipe $l$. 
The general sewer network design problem defined by Equations (1) to (11) is clearly a Mixed Integer Nonlinear Programming (MINLP) problem which cannot be solved using conventional methods. Generally, decision variables of this problem are discharge direction in the sewer pipes presenting sewer network layout, the sewer network components such as pump and drop locations and heights, sewer pipes diameters, average cover depths of the sewer pipes, and sewer pipes slopes. The complexity of the problem is mostly due to the topological constraint requiring an efficient method for its implementation if an optimal solution to the whole problem is required.

\section{Proposed Methods for Layout and Size Optimization of Sewer Network}

Here the complex problem of joint layout and components size determination of a pumped/gravitational sewer network is solved by an effective hybrid method. The complexity of the problem is essentially due to the scale of the problem, nonlinear and piecewise objective function, integer and discrete decision variables and a large number of nonlinear constraints. Solution of the problem in hand requires that network layout, pipe diameters, pipe slopes, average pipe cover depths, and finally pump and drop heights and locations are determined. Since the pump/drop locations and heights determines the pipes nodal elevations meeting at network nodes (manholes) and vice versa, the pump/drop locations and heights can be determined using the pipe slopes assuming a minimum cover depth at the network inlets. The set of decision variables of the problem can, therefore, be reduced to network layout, pipe sizes and pipe slopes.

A hybrid ACOA based model, referred to as ACOATGA-NLP, is proposed here for the efficient and effective solution of the problem. In the proposed model, the pipe diameters and the layout of the network are simultaneously determined by the ACOA equipped with a TGA, while the remaining part of the solution namely pipe slopes determination is carried out by a NLP method. In this method, the ACOA is responsible for pipe diameters determination while the TGA is used to guides the ants to create the required tree structure of the network when deciding on the pipe diameters. Generally, the step by step procedure of TGA for construction of a spanning tree structure out of base layout is presented in Figure 1. Another model, referred to as ACOA-NLP, is also suggested for comparison purpose in which the pipe diameters are suggested by ACOA in a conventional manner. The layout of the sewer network is then decided using an ad-hoc engineering based concept and finally the pipe slopes of the network with known layout and pipe diameters are determined by a NLP method.

Proposed methods can be considered as the extensions of a method already proposed by authors (Moeini, 2013) for optimal sizing of sewer network with fixed layout in which the ACOA was hybridized by NLP method. The second method, ACOA-NLP, is an ad-hoc extension of the method of Moeini (2013) while the first method, ACOA-TGA-NLP, is an intelligent and novel extension of the existing method of Moeini (2013). Furthermore, the proposed methods can also be considered as an attempt to overcome the very important limitations of two methods of Moeini and Afshar (2012, 2013) which could not consider pump and drop in the network. Details of the proposed methods are explained as follows.

\subsection{ACOA-NLP Method}

In the ACOA-NLP, the ACOA is hybridized with NLP method for optimal design of joint layout and size of sewer network. In this method, the pipe diameters of the sewer network, as discrete decision variables of the problem, are determined by the ACOA. This requires that the problem under consideration is defined as a graph. Construction of the graph for the application of the ACOA requires that decision points, options available at each decision point, and the costs associated with each of these options are defined. Here, the pipes of the base layout are taken as decision points, and the set of commercially available pipe diameters, $D$, is used to represent the options available at each decision point. The graph representation of the problem for the application of the ACOA in a conventional manner is shown in Figure 2, where small lines represent the options (pipe diameters, $j=1, \ldots, J$ ) at each decision point $i(i=1, \ldots, I) ; d_{\min }=$ minimum sewer pipe dia-

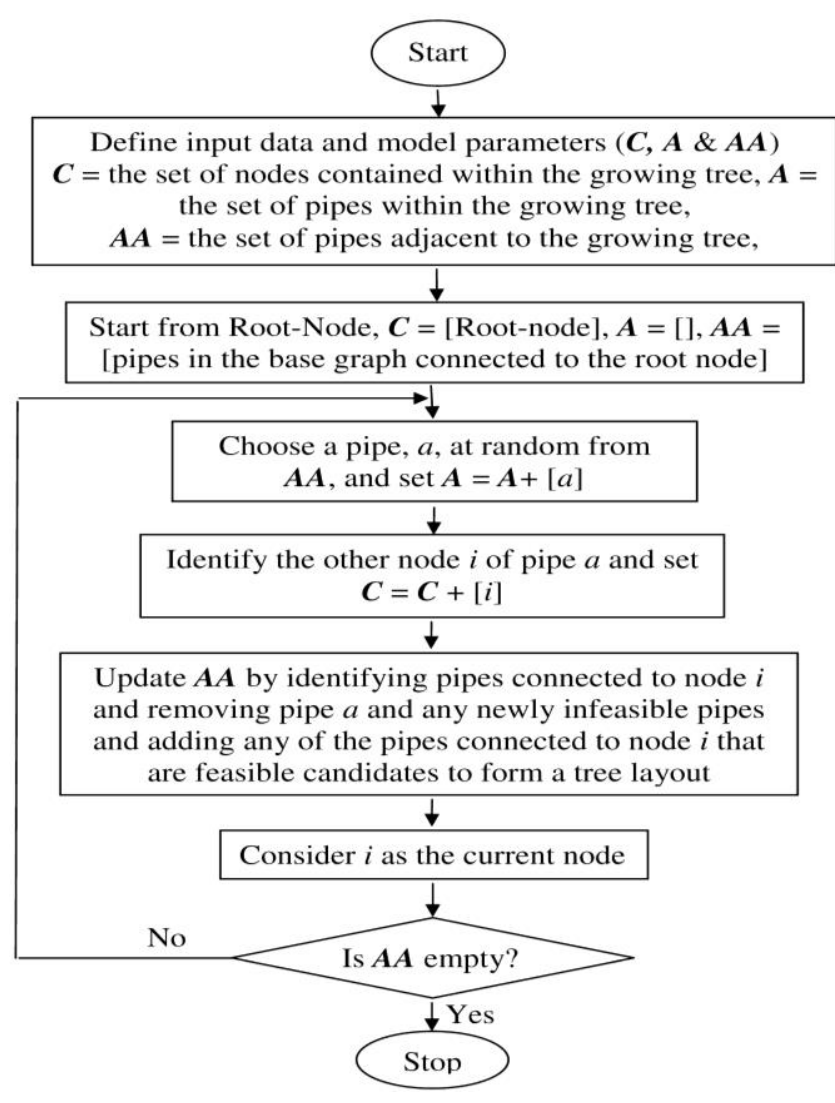

Figure 1. Procedure of TGA for construction of a spanning tree out of base layout. 

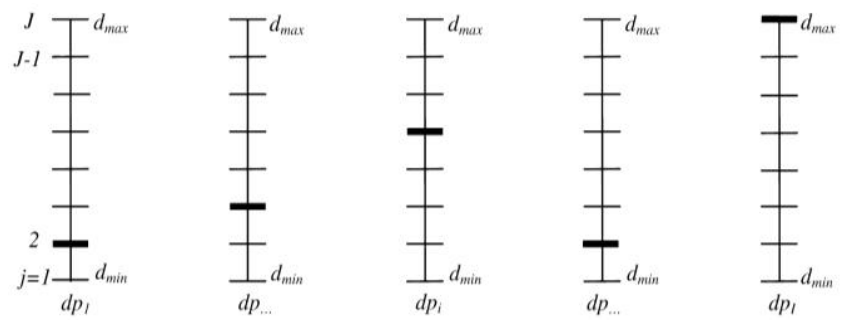

Figure 2. Problem graph used for application of ACOA-NLP.

meter; $d_{\max }=$ maximum sewer pipe diameter; and finally the bold lines represent a trial solution on the graph constructed by an arbitrary ant. The step by step procedure defined in Figure 3 can be used to determine all pipe diameters of a base layout.

Once the pipe diameters are defined, an ad-hoc engineering based process is used to create, if possible, a feasible layout with tree structure for the network. This process has already been suggested and used by Moeini and Afshar (2012) and, therefore, will not be addressed here any more. Having determined pipe diameters and layout of the sewer network, the remaining task is to determine the pipe slopes of the network. This is carried out using a method described and used by Moeini (2013) for optimal component sizing of the sewer network with fixed layout. Having determined the pipe diameters, the pipe slopes, as the continuous decision variables, are determined by the solution of following NLP problem.

Assuming known pipe diameters $\overline{d_{l}} ; l=1,2, \ldots, N$, determine the pipe slopes $S_{l} ; l=1,2, \ldots, N$ to minimize the objective function of Equation (1) subject to the constraints (5) to (9) already defined.

This problem is a constrained NLP problem which is difficult to solve using NLP solvers. To alleviate the problem, the sewer flow velocity constraints of Equation (6) and relative flow depth constraints of Equation (8) are recast into a set of box constraints and combined with the minimum slope constraint of Equation (7) leading to a considerable reduction of the search space size and, therefore, increased efficiency of the method. The final form of the constraints on the pipe slopes can be defined as (Moeini, 2013):

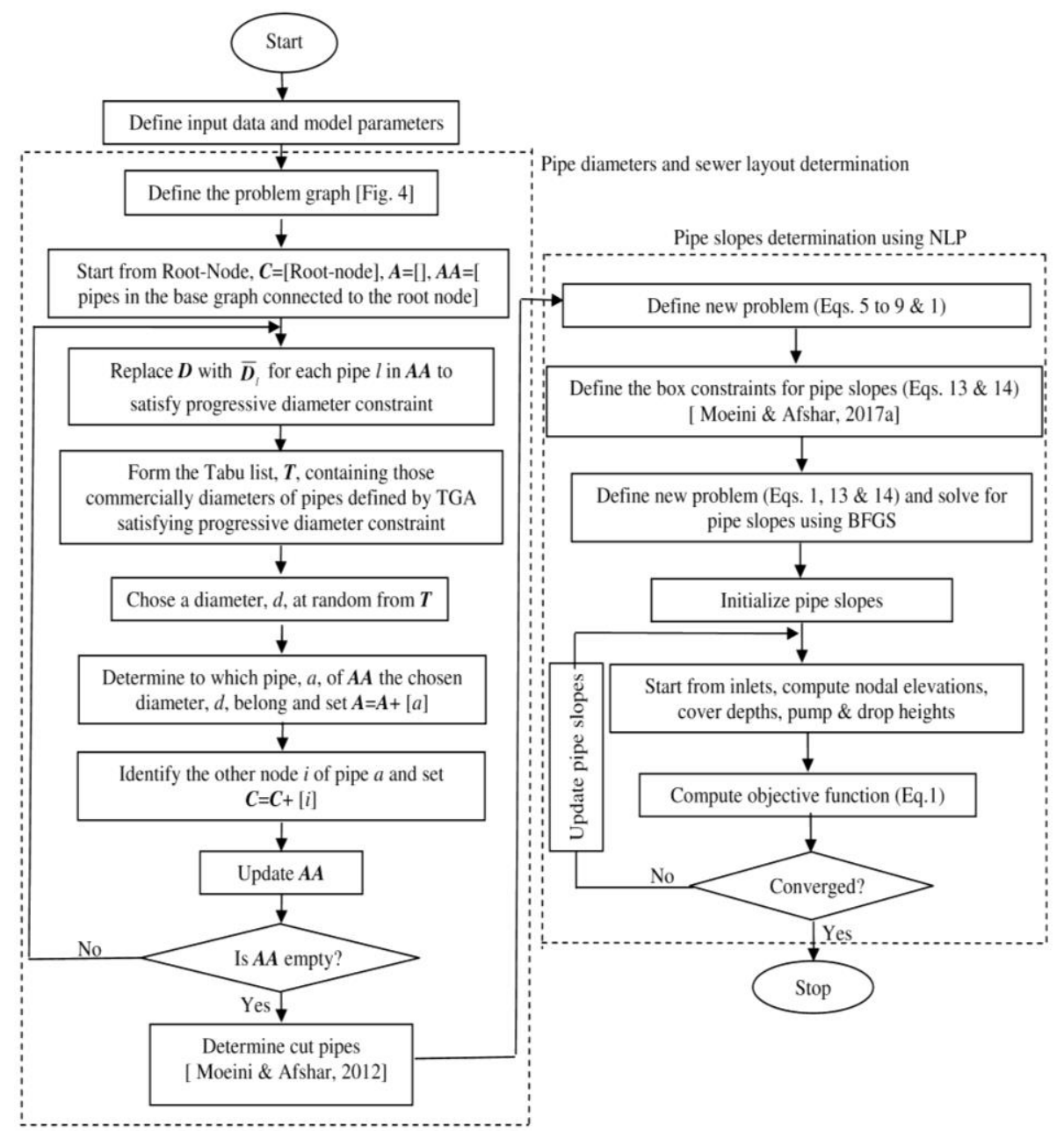

Figure 3. Procedure of ACOA-NLP for construction of a trial solution by an arbitrary ant. 


$$
\begin{aligned}
& E_{\min } \leq E_{l} \leq E_{\max } \quad \forall l=1, \ldots, N \\
& S_{l} \geq \bar{S}_{l}^{\min }=\operatorname{Max}\left(S_{\min }, S_{l}^{\min , 1}, S_{l}^{\min , 2}\right) \\
& S_{l} \leq \bar{S}_{l}^{\max }=\operatorname{Min}\left(S_{l}^{\max , 1}, S_{l}^{\max , 2}\right)
\end{aligned}
$$

with

$$
\begin{array}{ll}
S_{l}^{\min , 1}=\left(\frac{n V_{\min }}{\left(R_{l}^{\max }\right)^{(2 / 3)}}\right)^{2} & S_{l}^{\max , 1}=\left(\frac{n V_{\max }}{\left(R_{l}^{\min }\right)^{(2 / 3)}}\right)^{2} \\
S_{l}^{\min , 2}=\left(\frac{n V_{l, \min }}{\left(R_{l}^{\max }\right)^{(2 / 3)}}\right)^{2} & S_{l}^{\max , 2}=\left(\frac{n V_{l, \max }}{\left(R_{l}^{\min }\right)^{(2 / 3)}}\right)^{2}
\end{array}
$$

where $S_{l}^{\min , 1}, S_{l}^{\max , 1}=$ minimum and maximum slopes of sewer pipe $l$ calculated based on sewer flow velocity constraint; $S_{l}^{\max , 2}, S_{l}^{\min , 2}=$ maximum and minimum slopes of sewer pipe $l$ calculated based on minimum, $\beta_{\min }$, and maximum, $\beta_{\max }$, allowable relative flow depth constraints; $V_{\max }=$ maximum allowable flow velocity of sewer; $V_{\min }=$ minimum allowable flow velocity of sewer; $R_{l}^{\max }=$ maximum hydraulic radius of the sewer pipe $l ; R_{l}^{\text {min }}=$ minimum hydraulic radius of the sewer pipe $l ; V_{l, \max }=$ maximum flow velocity of the sewer pipe $l$ corresponding to the $\theta_{l}^{\max } ; V_{l, \min }=$ minimum flow velocity of the sewer pipe $l$ corresponding to the $\theta_{l}^{\min } ; \theta_{l}^{\max }=$ maximum central angle of the sewer pipe $l ; \theta_{l}^{\min }=$ minimum central angle of the sewer pipe $l$.

The continuous nonlinear optimization problem defined by the objective function of Equation (1) subject to the easy to apply box constraints of Equations (13) and (14) is now solved for pipe slopes determination using the method of Broyden-Fletcher-Goldfarb-Shanno (BFGS). Hydraulic parameters such as velocity and flow depth are then calculated in a conventional manner while useful relations of Swamee et al. (1987) and Sharma and Swamee (2008) could have also been used.

Having calculated the pipe sizes, network layout and pipe slopes, the average pipe cover depths and the pump/drop locations and heights $\left(h_{p} \& h_{m}\right)$ are calculated in the following manner. Assuming a minimum cover depth for all the network inlets, the downstream nodal elevations are calculated using the known pipe slopes. The minimum of the downstream nodal elevations of all entering pipes is considered as the upstream nodal elevation of the leaving pipe for each network node and this approach is continued until upstream and downstream nodal elevations of all network pipes are calculated. If the calculated downstream nodal elevation of a pipe violates the allowable minimum/maximum cover depth constraints, the pipe is lowered/lifted such that the downstream nodal cover depth is equal to the minimum/maximum cover depth leading to a drop/pumping station at the upstream node of the pipe. Having calculated the nodal elevation of pipe entering and leaving a node, the pump and drop heights and locations can be determined leading to a complete trial solution which is then used to calculate the problem objective function of
Equation (1). The objective function value is used by the optimizer to create new sampling points represented by the pipe slopes. The procedure is continued until convergence is achieved.

It should be, however, noted that the trial solutions so constructed by ACOA-NLP model may violate the progressive diameter constraint of the problem defined by Equation (10). To encourage the model to make decisions leading to feasible solutions, a higher cost is associated to the solutions that violate this constraint. This may be done via the use of a penalty method in which the total cost of the problem is considered as the sum of the problem cost and a penalty cost as:

Minimize $C_{p}=C+\alpha_{p} \times C S V$

where $C_{p}=$ penalized objective function; $C=$ original objective function defined by Equation (1); $C S V=$ a measure of the violation of constraint (10) defined as the number of pipes violating the corresponding constraint; and $\alpha_{p}=$ the penalty constant assumed large enough so that any infeasible solution has a total cost greater than that of any feasible solution and other parameters were defined before. It is worth noting that the penalized term in Equation (15) will be zero for feasible solutions.

Finally, the total cost of the final solution obtained is then passed to the ACOA as the objective function of the individual solution already created by the ACOA. Figure 3 illustrates the general procedure of ACOA-NLP method for construction of a trial solution by an arbitrary ant.

\subsection{ACOA-TGA-NLP Method}

In this novel method, ACOA is hybridized with the TGA and NLP leading to an efficient and effective method, referred to as ACOA-TGA-NLP, for layout and size optimization of pumped/gravitational sewer network. Hybridization of the ACOA with the TGA allows for the effective use of the incremental solution building capability of the ACOA to simultaneously construct tree-like feasible layouts out of the base layout while determining the pipe sizes. In this approach, the TGA is responsible to keep the ants' options limited to forming tree layouts while the ACOA determines the pipe sizes. Once the layout and pipe diameters are determined by ACOATGA part of the method, NLP method is used to calculate the pipe slopes in the same manner defined earlier for the ACOA-NLP method. This concept of hybridizing the ACOA with the TGA has already been used by Moeini and Afshar (2012) for joint layout and size optimization of gravitational sewer network. In the method of Moeini and Afshar (2012), however, a simplifying assumption of sewer flow at maximum relative flow depth was made to allow for the calculation of pipe slopes from diameters. This assumption is removed here by determining pipe slopes via solving an optimization problem leading to more effective methodology. Furthermore, the method of Moeini and Afshar (2012) did not account for the progressive diameter constraint during soluti- 


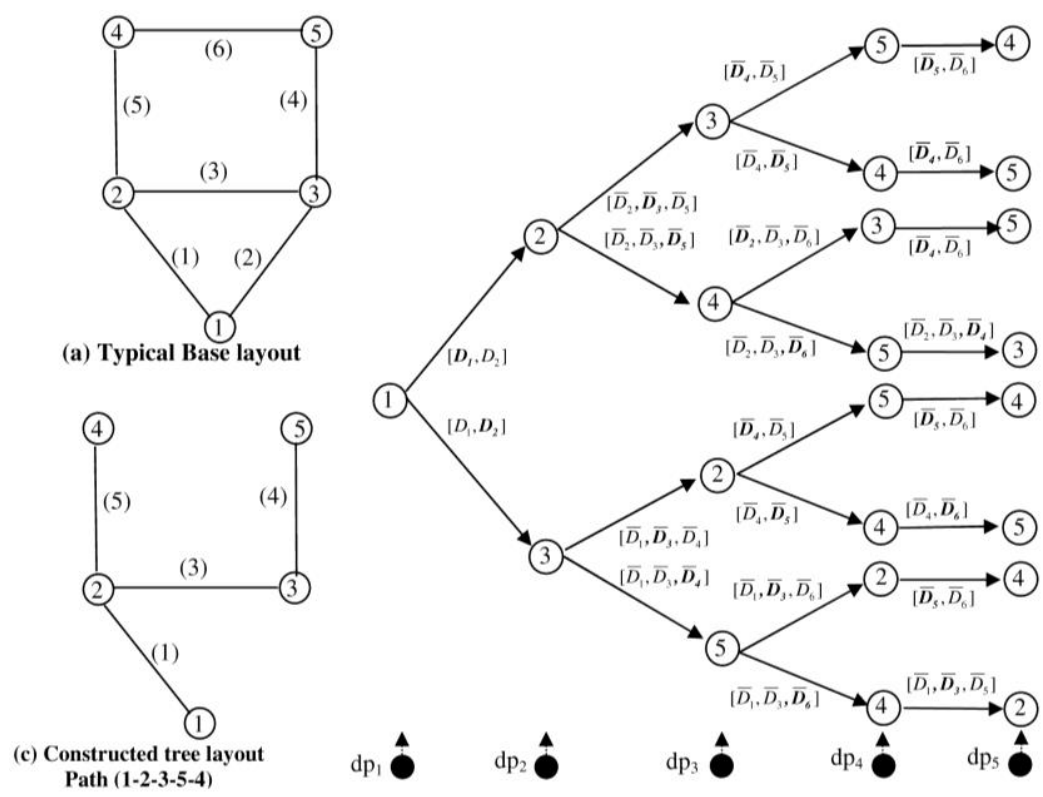

(b) Graph representation
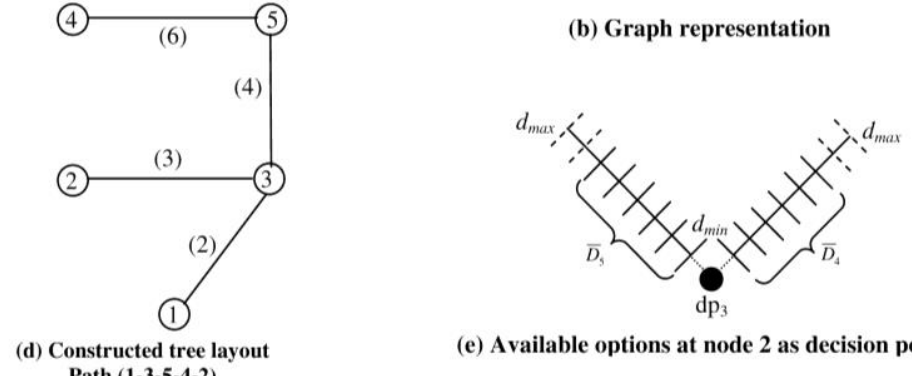

(e) Available options at node 2 as decision point 3

Figure 4. Graph representation of the typical problem for ACOA-TGA-NLP.

on construction.

In the proposed ACOA-TGA-NLP, the nodes of the base layout are taken as decision points of the graph and the options available at each decision point are defined by the aggregation of the commercially available diameters for all the pipes which can contribute to a tree-like layout which are defined by the TGA at each decision point while satisfying progressive diameter requirement of Equation (10). In this method, the number of available options at each decision point is clearly influenced by the decisions already taken and could, therefore, differ from one decision point to another. This is in contrast to the ACOA-NLP method defined earlier in which the pipes of the base layout were taken as the decision points with fixed number of options equal to the number of the commercially available pipe diameters. While in the ACOA-NLP, ants could start the solution construction, pipe size determination, from an arbitrary decision point, in ACOA-TGA-NLP, each ant starts from the root node and makes a decision before moving to the next decision point. The options available to the ants at each decision point are determined by the TGA, and the decision made by the ants determines which decision point to move to. The role of the TGA is to define the pipes of the base layout which can contribute to a tree layout. For this, a tabu list is created for each ant which includes some potential commercial diameters of the pipes already defined by the TGA satisfying progressive diameter constraint. Any decision of the ant by choosing one diameter from the tabu list will, therefore, lead to simultaneous definition of the pipe to be included in the tree layout and its diameter satisfying progressive diameter constraint. This process is continued until all decision points of the problem, base layout nodes, are covered leading to a trial partial solution represented by pipe diameters of a spanning tree layout satisfying the progressive diameter constraint.

This process is schematically illustrated in Figure 4. Figure $4 \mathrm{~b}$ shows the graphical representation of the proposed ACOA-TGA-NLP method for the typical problem of Figure 4(a) in which the circles represent the network nodes, the dark circles represent the decision points of the ACOA, the numbers in the circles represent the node numbers, the numbers in the parenthesis indicate the pipe numbers, $D_{l}$ represent the set of available commercial diameters to be used for pipe $l, \overline{D_{l}} \subseteq$ $D_{l}$ represent the set of available commercial diameters to be used for pipe $l$ satisfying progressive diameter constraint, the brackets represent the options available to the ant at each decision point to form a tree layout, and the bold $\overline{D_{l}}$ indicates that a diameter from $\overline{D_{l}}$ is chosen by the ant leading to the inclusion of pipe $l$ in the tree under construction. Any path on 


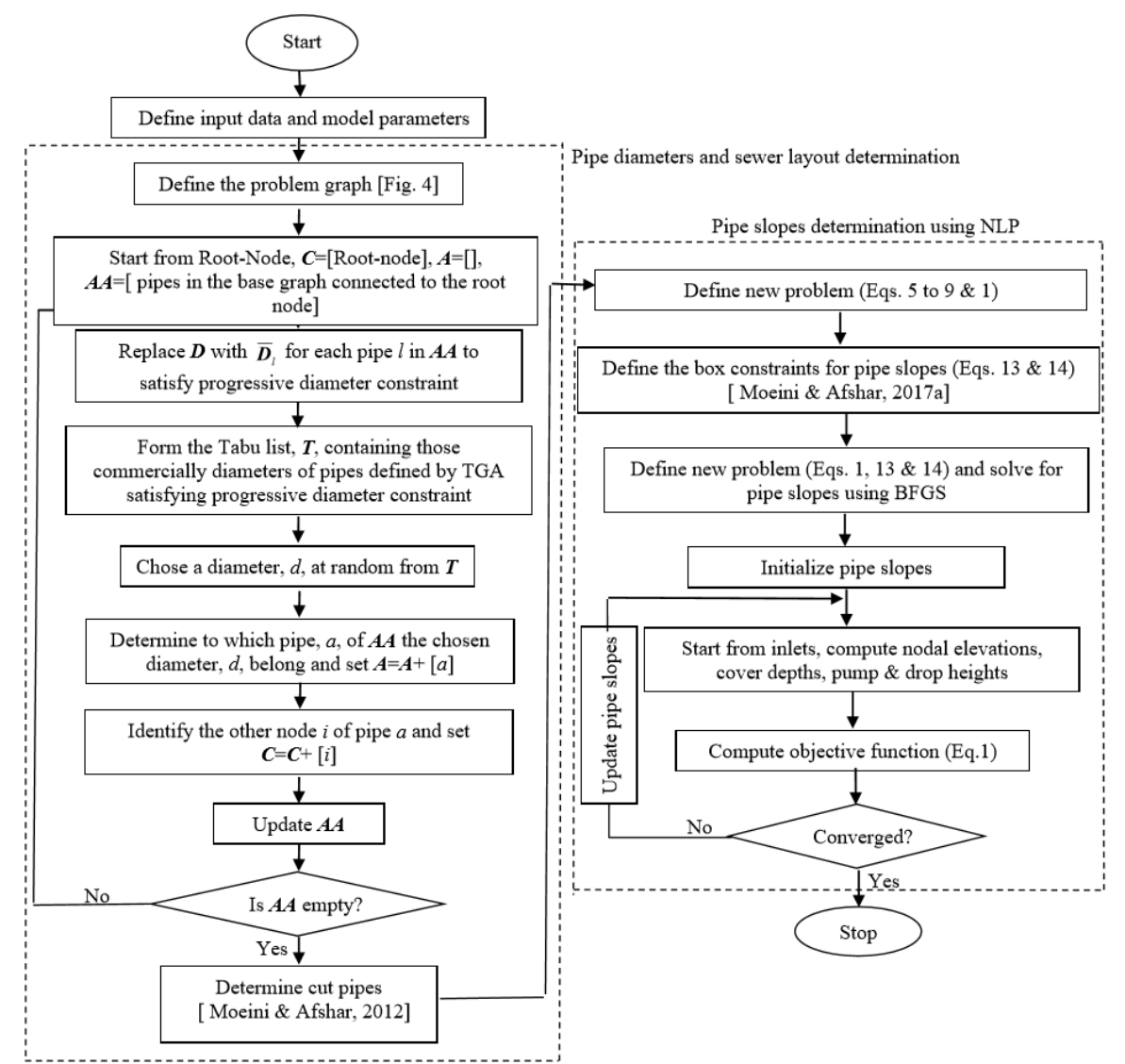

Figure 5. Procedure of ACOA-TGA-NLP for construction of a trial solution by an arbitrary ant.

the problem graph shown in Figure 4(b) represents pipe diameters of a spanning tree layout out of the base layout of Figure 4(a) satisfying the progressive diameter constraint, represented by the links with bold $\overline{D_{l}}$ s on the path. For example the path (1-2-3-5-4) on the graph represents a tree layout composed of pipes $1,3,4$ and 5 while the path (1-3-5-4-2) denotes another tree layout composed of pipes 2, 4, 6 and 3 which are presented in Figures $4 \mathrm{c}$ and $4 \mathrm{~d}$, respectively. Figure $4 \mathrm{e}$ shows the way the available options are formed at node 2 when considered as the third decision point $\left(d p_{3}\right)$ denoted by $\left|\overline{D_{4}}, \overline{D_{5}}\right|$ in which the dark circle represents the decision point, the diagonal small lines represent the commercial diameters of the corresponding pipes with the solid ones denoting the feasible ones satisfying progressive diameter constraint, diameters no bigger than the chosen diameter for pipe 3 and 1, and the dashed ones representing infeasible diameters.

The resulting spanning tree layout, however, will not include all the pipes present in the base layout and should be completed before the pipe slopes determination part of the solution process can be started. This is achieved by inserting the remaining pipe into the constructed layout while making a cut at either end node to restore the tree structure of the final layout (Moeini and Afshar, 2012). A minimum commercially available diameter is considered for cut pipes to make sure that the progressive diameter constraint is automatically satis- fied. Having determined the layout of the sewer network and corresponding pipe diameters, the pipe slopes are determined using the NLP method, as defined earlier. The pipe slopes are then used to calculate the pipes upstream and downstream nodal elevations from which the pipe average cover depths and the pump and drop locations and heights can be extracted as defined before leading to a complete trial solution. Once again, the total penalized cost of the constructed solution is calculated and passed to the ACOA as the objective function of the individual solution created by the ACOA-TGA-NLP method. Figure 5 illustrates the general procedure of ACOA-TGANLP method for construction of a trial solution by an arbitrary ant.

\section{Test Example}

Performance of the proposed methods is now, at first, tested against a benchmark test example of sewer network design cited in Li and Matthew (1990). The sewer network is to be designed out of a base layout shown in Figure 6 with 56 nodes and 79 edges covering an area of 2.6 hectare where the circles represent the network nodes, the numbers at the adjacency of the circles represent the node numbers, the numbers in the parenthesis indicate the nodal elevations, and the numbers in the brackets represent the pipe numbers. There is only one outlet discharging to a waste water treatment plant at no- 
de number 56. The set of diameters ranging from $200 \mathrm{~mm}$ up to $2400 \mathrm{~mm}$ with values of $200,250,300,350,380,400,450$, $500,530,600,700,800,900,1000,1050,1200,1350,1400$, $1500,1600,1800,2000,2200$, and $2400 \mathrm{~mm}$ is used as the set of commercially available pipe diameters. Other parameters used to solve this problem are listed in Table 1.

Here the following relation is used for the construction, maintenance and operation cost parameters ( $\mathrm{Li}$ and Matthew, 1990):

$$
\begin{aligned}
& \mathrm{C}_{\text {con }}=\sum_{l=1}^{N} L_{l} K_{\text {pip }}\left(d_{l}, E_{l}\right)+\sum_{m=1}^{M} K_{\text {man }}\left(h_{m}\right)+\sum_{p=1}^{P} K_{\text {pum }}\left(q_{p}\right) \\
& \mathrm{C}_{\text {main }}=\sum_{t=1}^{T} 0.042 C_{\text {con }} \\
& \mathrm{C}_{\mathrm{opr}}=\sum_{t=1}^{N} \sum_{p=1}^{P} \frac{85.848 q_{p} h_{p} \varphi}{\varepsilon \eta}
\end{aligned}
$$

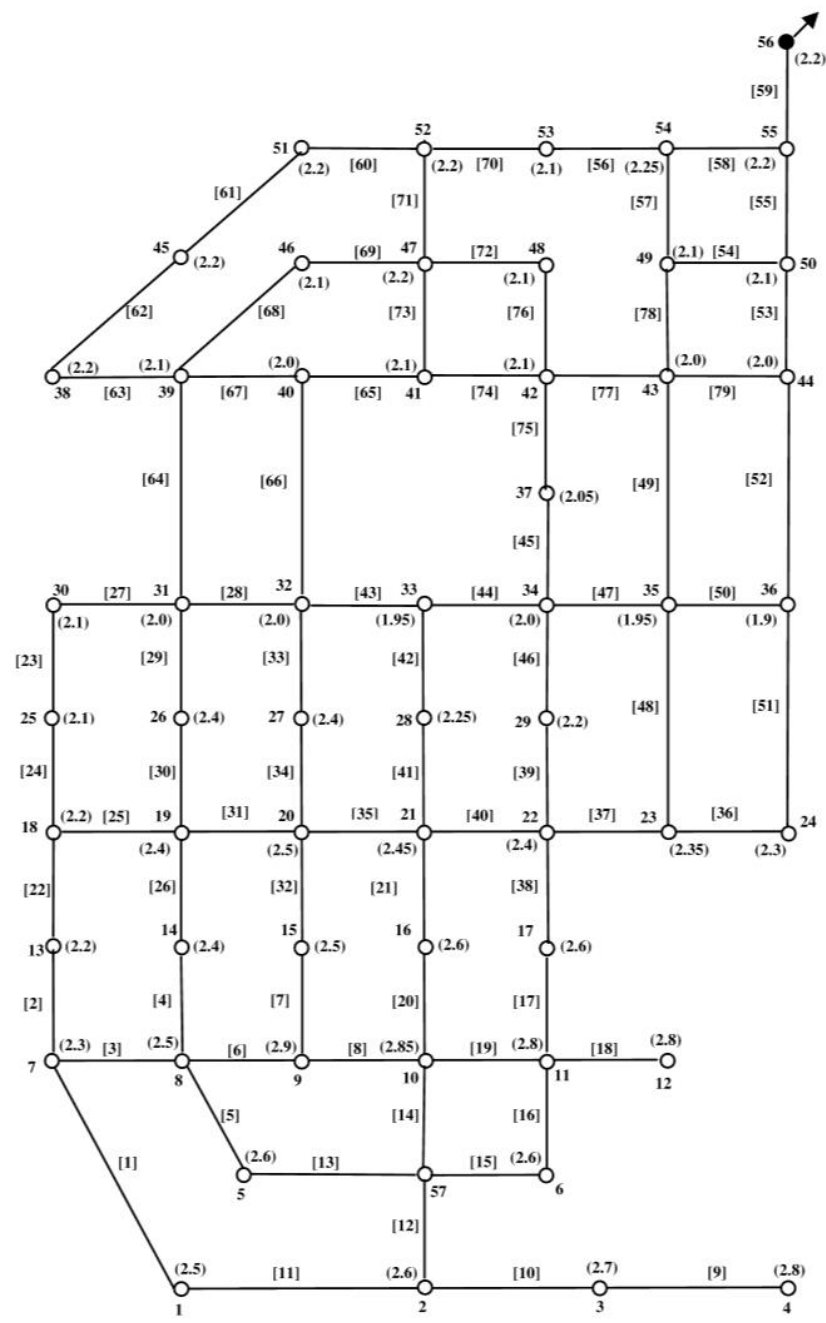

Figure 6. Base layout of the first test example with nodal ground elevations. where:

$$
\begin{aligned}
& K_{p i p}= \\
& {\left[\begin{array}{l}
4.27+93.59 d_{l}{ }^{2}+2.86 E_{l} d_{l}+2.39 E_{l}{ }^{2} \text { if } d_{l} \leq 1 \text { and } E_{l} \leq 3 \\
36.47+88.96 d_{l}{ }^{2}+8.7 E_{l} d_{l}+1.78 E_{l}{ }^{2} \text { if } d_{l} \leq 1 \text { and } E_{l}>3 \\
20.5+149.27 d_{l}{ }^{2}-58.96 E_{l} d_{l}+17.75 E_{l}{ }^{2} \text { if } d_{l}>1 \text { and } E_{l} \leq 4 \\
78.44+29.25 d_{l}{ }^{2}+31.8 E_{l} d_{l}-2.32 E_{l}{ }^{2} \text { if } d_{l}>1 \text { and } E_{l}>4
\end{array}\right]} \\
& K_{\text {man }}= \\
& {\left[\begin{array}{l}
136.67+166.19 d_{e x}{ }^{2}+3.5 h_{m} d_{e x}+16.22 h_{m}{ }^{2} \quad \text { if } d_{e x} \leq 1 \text { and } h_{m} \leq 3 \\
132.91+790.94 d_{e x}{ }^{2}-280.23 E_{l} d_{e x}+34.97 h_{m}{ }^{2} \text { if } d_{e x} \leq 1 \text { and } h_{m}>3 \\
209.74+57.53 d_{e x}{ }^{2}+10.93 h_{m} d_{e x}+19.88 h_{m}{ }^{2} \quad \text { if } d_{e x}>1 \text { and } h_{m} \leq 4 \\
210.66-113.04 d_{e x}{ }^{2}+126.43 h_{m} d_{e x}-0.6 h_{m}{ }^{2} \text { if } d_{e x}>1 \text { and } h_{m}>4
\end{array}\right]} \\
& K_{\text {pum }}=270021+316.42 q_{p}-0.1663 q_{p}{ }^{2}
\end{aligned}
$$

where $C_{c o n}=$ construction cost function of sewer network; $C_{\text {main }}=$ maintenance cost function of sewer network; $C_{o p r}=$ operation cost function of sewer network; $N=$ total number of sewer pipes; $M=$ total number of manholes; $P=$ total number of pumping stations; $L_{l}=$ the length of pipe $l(l=1, \ldots, N)$; $K_{\text {pip }}=$ the unit cost of sewer pipe provision and installation defined as a function of its diameter $\left(d_{l}\right)$ and average cover depth $\left(E_{l}\right) ; K_{\operatorname{man}}=$ the cost of manhole construction as a function of manhole height $\left(h_{m}\right) ; K_{\text {pum }}=$ the cost of pumping station construction as a function of pumping discharge $\left(q_{p}\right) ; h_{p=}$ pump height; $\phi=$ electricity price; $\varepsilon=$ correction coefficient; $\eta=$ efficiency of pump; $d_{e x}=$ diameter of sewer pipe leaving from manhole, $T=$ design period and other parameters are defined before.

To further test the ability of the proposed method to solve large scale network, a second hypothetical test example is also devised and solved. The base layout of thishypothetical sewer network, shown in Figure 7, has 81 nodes and 144 edges considered to collect the sewer of a flat area with the gr-

Table 1. Design Parameters for the Benchmark Test Example

\begin{tabular}{ll}
\hline Parameters & Parameter functions and values \\
\hline Maximum velocity & $5(\mathrm{~m} / \mathrm{s})$ \\
Minimum velocity & $0.7(\mathrm{~m} / \mathrm{s})\left[\right.$ if $\left.\mathrm{d}_{1} \leq 0.5(\mathrm{~m}), \mathrm{Q}_{1}>15(\mathrm{~L} / \mathrm{s})\right]$ \\
& $0.8(\mathrm{~m} / \mathrm{s})\left[\right.$ if $\left.\mathrm{d}_{1}>0.5(\mathrm{~m}), \mathrm{Q}_{1}>15(\mathrm{~L} / \mathrm{s})\right]$ \\
Minimum slope & $0.003\left[\right.$ if $\left.\mathrm{Q}_{1} \leq 15(\mathrm{~L} / \mathrm{s})\right]$ \\
Maximum allowable & $0.6\left[\right.$ if $\left.\mathrm{d}_{1} \leq 0.3(\mathrm{~m})\right]$ \\
relative flow & $0.7\left[\right.$ if $\mathrm{d}_{1} \geq 0.35(\mathrm{~m})$ and $\left.\mathrm{d}_{1} \leq 0.45(\mathrm{~m})\right]$ \\
& $0.75\left[\right.$ if $\mathrm{d}_{1} \geq 0.5(\mathrm{~m})$ and $\left.\mathrm{d}_{1} \leq 0.9(\mathrm{~m})\right]$ \\
& $0.8\left[\right.$ if $\left.\mathrm{d}_{1} \geq 1(\mathrm{~m})\right]$ \\
Maximum cover depth & $10(\mathrm{~m})$ \\
Minimum cover depth & $1(\mathrm{~m})$ \\
Design period & $10($ years $)$ \\
$\phi$ & $0.0996(\mathrm{yuan} / \mathrm{kwh})$ \\
$\eta$ & $80 \%$ \\
\hline
\end{tabular}




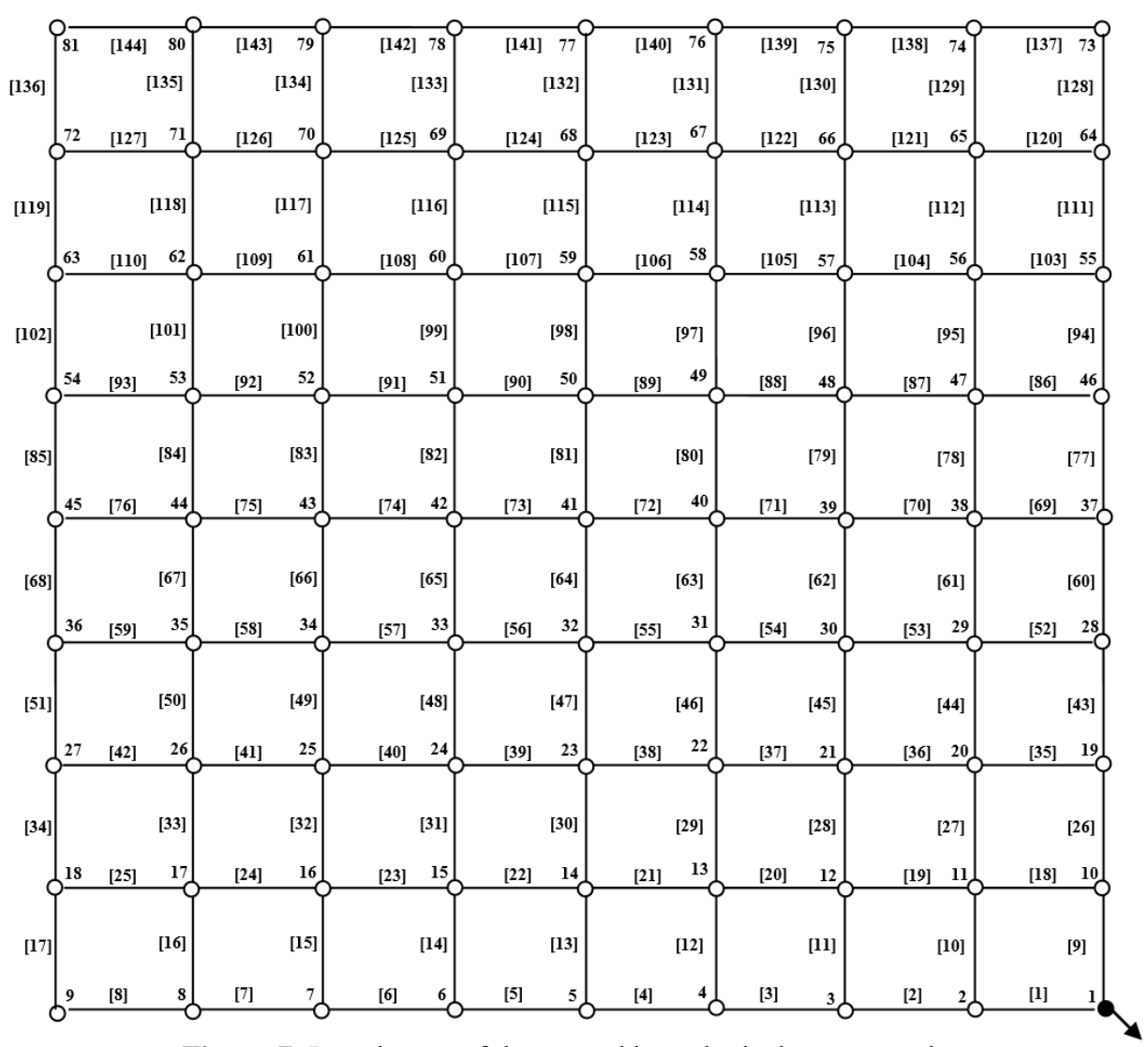

Figure 7. Base layout of the second hypothetical test example.

ound elevation of 1000 meter for all nodes. The population of the area is assumed to be uniformly distributed over the area with the value of 4000 person per hectare at the end of the design period. The average water consumption per person per day at the end of the design period is taken as 250 litres per person per day. The return factor used for calculation the sewer discharge of the area is assumed to be 0.8. All pipes lengths of the network are assumed to be constant and equal to 100 meter. All other parameters including hydraulic and availability constrain parameters and cost functions are the same as the first example shown in Table 1.

First benchmark test example was solved by Li and Mathew (1990) using Shortest Path Spanning Tree (SPST) and Searching Direction Method (SDM) for layout determination and DDDP for pipe size determination and recently by Haghighi (2013) using GA for layout determination and DDDP for pipe size optimization. This example is considered here to verify the versatility and efficiency of the proposed ACOANLP and ACOA-TGA-NLP methods. Furthermore, this problem is also solved using the methods of Moeini and Afshar (2012) referred to as ACOA and ACOA-TGA for comparison purpose. These methods are based on the assumption of sewer flow at maximum relative depth allowing for direct calculation of pipe slopes from pipe diameters. Second hypothetical test example is also solved here using proposed ACOA-TGANLP, ACOA-NLP, ACOA-TGA and ACOA methods. A set of preliminary runs is first conducted to find the proper values of Max-Min Ant System (MMAS) parameters (Stutzle and Hoos, 2000) as shown in Table 2 for proposed formulations. Details of sensitivity analysis for all parameters are not presented here to avoid lengthy paper except for the $P_{\text {best }}$ parameter which is shown in Figure 8. Figure 8 shows the average solution costs for different values of $P_{\text {best }}$ when the ACO-TGA-NLP method is used to solve first benchmark test example. It is worth noting that best result is obtained for the value of $0.2\left(P_{\text {best }}=\right.$

Table 2. Values of MMAS Parameters

\begin{tabular}{llllllll}
\hline Formulation & Iteration & Ant & $\begin{array}{l}\text { Function } \\
\text { evaluation }\end{array}$ & $\alpha$ & $\beta$ & $\rho$ & Pest \\
\hline ACOA & 1000 & 200 & 200000 & 1 & 0 & 0.95 & 0.2 \\
ACOA-TGA & 1000 & 200 & 200000 & 1 & 0 & 0.95 & 0.2 \\
ACOA-NLP & 1000 & 100 & 100000 & 1 & 0 & 0.95 & 0.2 \\
ACOA-TGA-NLP & 1000 & 100 & 100000 & 1 & 0 & 0.95 & 0.2 \\
\hline
\end{tabular}


Table 3. Maximum, Minimum and Average Solution Costs over 10 Runs Obtained Using Different Methods

\begin{tabular}{|c|c|c|c|c|c|c|c|}
\hline \multirow[b]{2}{*}{ Test example } & \multirow[b]{2}{*}{ Formulation } & \multicolumn{3}{|c|}{ Cost value } & \multirow[b]{2}{*}{$\begin{array}{l}\text { Scaled } \\
\text { standard } \\
\text { deviation }\end{array}$} & \multirow{2}{*}{$\begin{array}{l}\text { No. of runs } \\
\text { with final } \\
\text { feasible } \\
\text { solution }\end{array}$} & \multirow[b]{2}{*}{$\begin{array}{l}\text { Averaged CPU } \\
\text { time (min) }\end{array}$} \\
\hline & & Minimum & Maximum & Average & & & \\
\hline \multirow{4}{*}{$\begin{array}{l}\text { First } \\
\text { (Li and } \\
\text { Matthew, } \\
1990 \text { ) }\end{array}$} & ACOA & --- & --- & --- & --- & 0 & 7 \\
\hline & ACOA-TGA & --- & --- & --- & --- & 0 & 10 \\
\hline & ACOA-NLP & $4.93 * 10^{6}$ & $9.41 * 10^{7}$ & $1.55^{*} 10^{7}$ & 1.7906 & 9 & 305 \\
\hline & ACOA-TGA-NLP & $1.98 * 10^{6}$ & $2.86 * 10^{6}$ & $2.35 * 10^{6}$ & 0.0953 & 10 & 132 \\
\hline \multirow{4}{*}{$\begin{array}{l}\text { Second } \\
\text { (hypothetical) }\end{array}$} & $\mathrm{ACOA}$ & --- & --- & --- & --- & 0 & 10 \\
\hline & ACOA-TGA & --- & --- & --- & --- & 0 & 15 \\
\hline & ACOA-NLP & $1.64 * 10^{6}$ & $3.39 * 10^{6}$ & $2.17 * 10^{6}$ & 0.2670 & 10 & 457 \\
\hline & ACOA-TGA-NLP & $0.91 * 10^{6}$ & $3.03 * 10^{6}$ & $1.99 * 10^{6}$ & 0.2304 & 10 & 198 \\
\hline
\end{tabular}

0.2) for this text example using ACO-TGA-NLP. In addition, all the runs are carried out on a $3 \mathrm{GHZ}$ Pentium PC.

Table 3 shows the results of 10 runs carried out using different randomly generated initial guess along with the scaled standard deviation and averaged CPU time requiring for each run and the number of final feasible solutions. It is clearly seen from Table 3 that all measures of the quality of the final solution such as the minimum, maximum, average costs and the number of final feasible solutions are improved when using proposed methods and in particular proposed ACOATGA-NLP. In fact, while ACOA-NLP and ACOA-TGA-NLP methods could produce 9 and 10 final feasible solutions for first test example and 10 and 10 final feasible solutions for second test example, the ACOA and ACOA-TGA methods of Moeini and Afshar (2012) could not produce any feasible solution for both test examples. This is of course due to limiting topological condition of the sewer network area. The fact that ACOA-TGA-NLP has been able to outperform the ACOA-NLP in every aspect is due to the fact that solutions constructed by the ACOA-TGA-NLP will never face layout, flow velocity, relative flow depth and progressive diameter infeasibilities.

Figures 9 and 10 show the optimal tree-like layout and pipe diameters obtained by ACOA-TGA-NLP for the first and second test examples respectively, where the circles represent

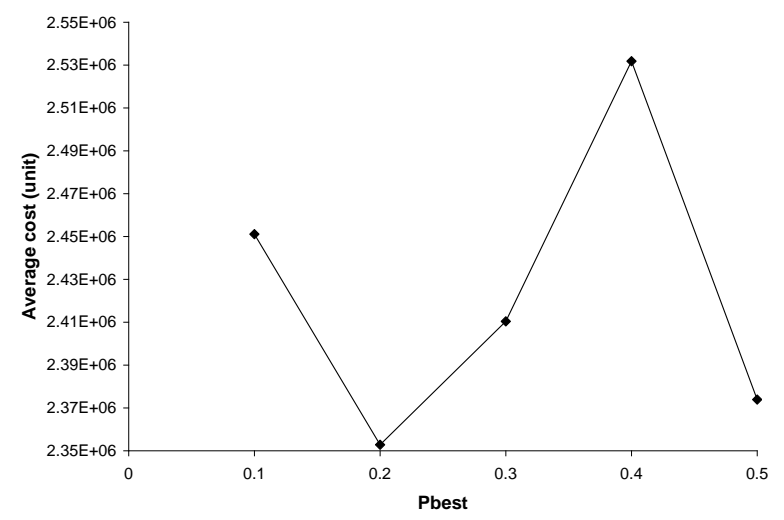

Figure 8. Average solution costs obtained by ACO-TGA-NLP for the first test example using different $P_{\text {best }}$. the network nodes, the numbers at the adjacency of the circles represent the node numbers, the numbers in the brackets represent the pipe numbers and the numbers in the parenthesis indicate the optimal pipe diameters. The optimal characteristics of the network obtained for the first test example is shown in Table S1. Figure 11 shows convergence curves of the minimum solution costs obtained in ten runs using proposed hybrid methods for the first test example indicating superior performance of the ACOA-TGA-NLP compared to

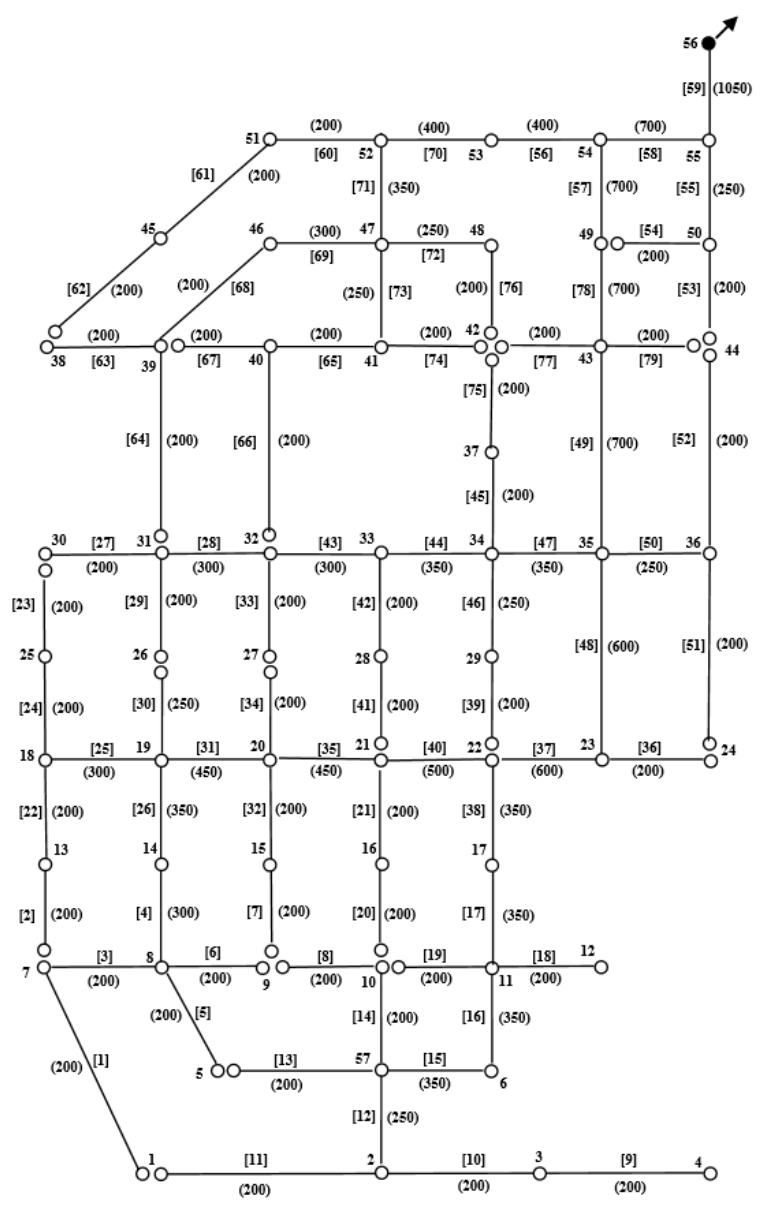

Figure 9. Optimal tree-like layout and pipe diameters of the first test example obtained by ACOA-TGA-NLP. 


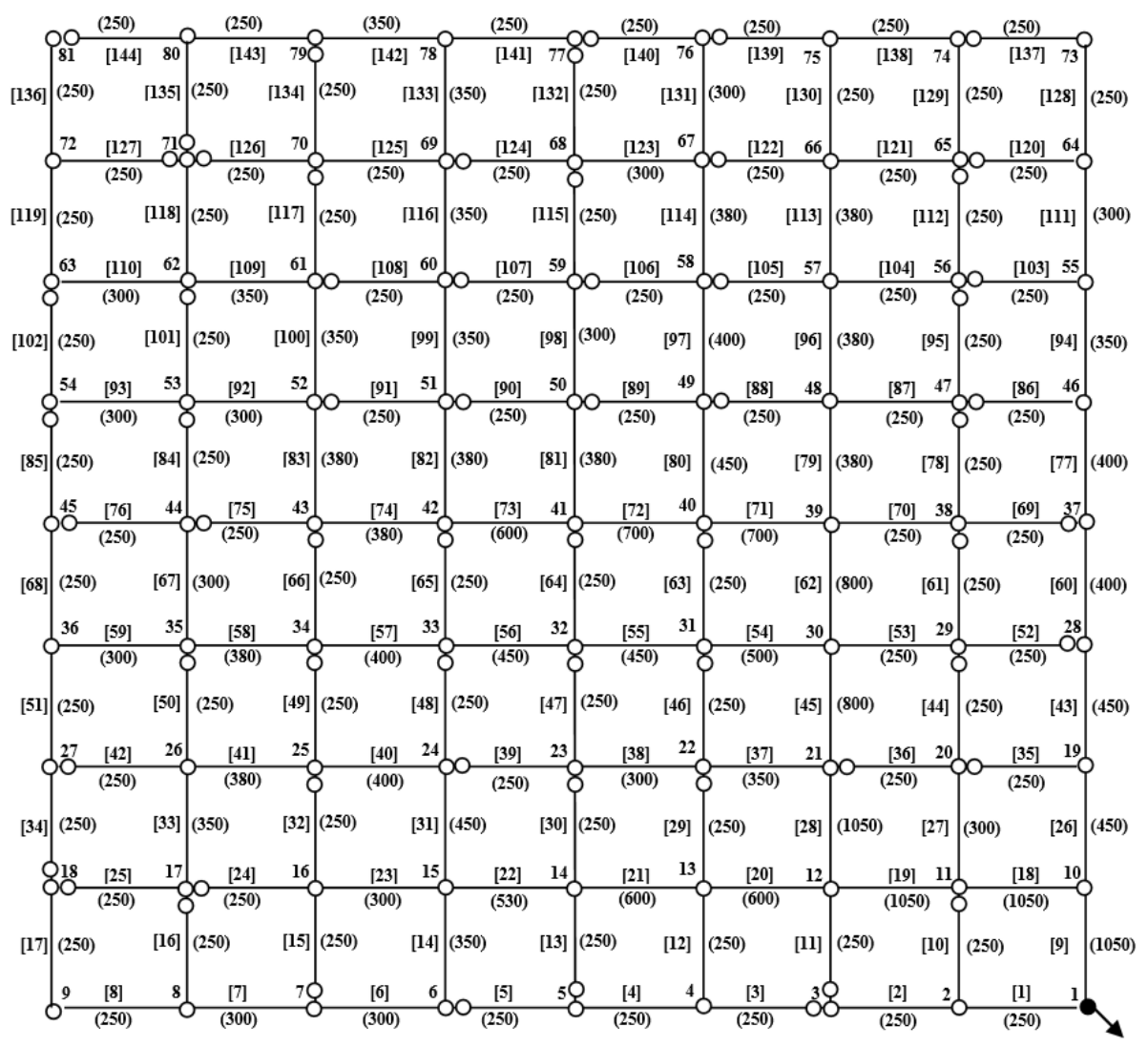

Figure 10. Optimal tree-like layout and pipe diameters of the second test example obtained by ACOA-TGA-NLP.

ACOA-NLP. It is clearly seen that the solution costs of ACOA-TGA-NLP remain lower than those of ACOA-NLP during the evolution process and in particular at initial iterations leading to lower cost final solution. This is because most of the solutions created by ACOA-TGA-NLP are feasible with regard to layout, flow velocity, relative flow depth and progressive diameter constraints. This is due to the fact that in ACOA-TGA-NLP method, the TGA is used to guides the ants to create the required tree structure of the network while in

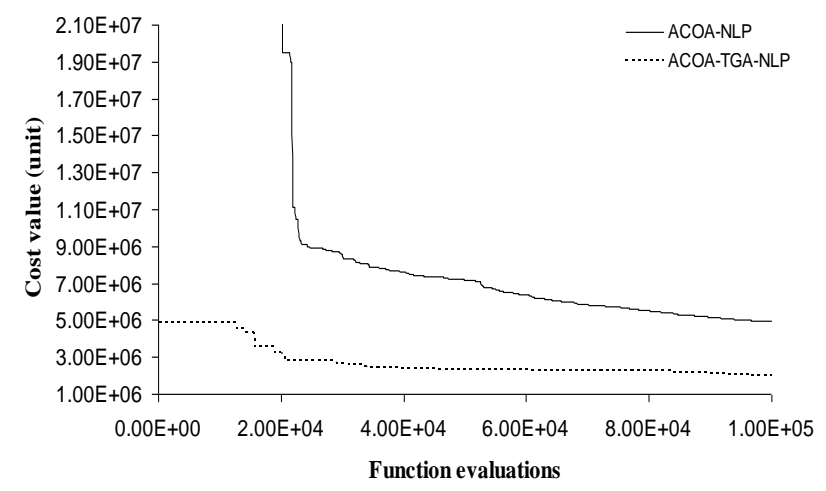

Figure 11. Variation of minimum solution costs using ACOA-NLP and ACOA-TGA-NLP for the first test example.
ACOA-NLP method the layout of the sewer network is constructed using an ad-hoc engineering based concept. Consequently, most of the constructed layouts by the ACOA-NLP method are, therefore, infeasible at the start of the process while those of ACOA-TGA-NLP are all feasible. This is the most important reason why the cost of ACOATGA-NLP solutions is significantly lower than those of ACOA-NLP even at the start of the process.

Table 4 compares the best results obtained by the proposed ACOA-TGA-NLP with some other available results for the first test example. Comparison of the results obtained by Li and Matthew (1990) and Haghighi (2013) with those produced here indicates that proposed ACOA-TGA-NLP has superior performance for the test example considered. $\mathrm{Li}$ and Matthew (1990) obtained optimal solutions of $2.73 * 10^{6}$ unit cost using DDDP for pipe size determination for existing layout, $3.25 * 10^{6}$ and $2.42 * 10^{6}$ unit costs using SPST and SDM for layout determination, respectively, and DDDP for pipe size determination. Later, Haghighi (2013) obtained optimal solution of $2.25 * 10^{6}$ unit cost using using GA for layout determination and DDDP for pipe size optimization. These can be compared with the unit cost of $1.98 * 10^{6}$ obtained using proposed ACOA-TGA-NLP indicating superiority of the proposed method. It is worth noting that the first solution of $\mathrm{Li}$ and Matthew (1990) contained two pumping station located at node numbers 9 and 10, the second solution contained two pumping stations at unreported locations, and the third soluti- 
Table 4. Comparison of the Results Obtained with Different Methods for the First Test Example

\begin{tabular}{|c|c|c|c|c|c|}
\hline Cost value & $\begin{array}{l}\text { Existing layout and } \\
\text { DDDP for sizing }\end{array}$ & $\begin{array}{l}\text { SPST for layout and } \\
\text { DDDP for sizing }\end{array}$ & $\begin{array}{l}\text { SDM for layout and } \\
\text { DDDP for sizing }\end{array}$ & $\begin{array}{l}\text { Present Work } \\
\text { (ACOA-TGA-NLP) }\end{array}$ & $\begin{array}{l}\text { GA for layout and } \\
\text { DDDP for sizing }\end{array}$ \\
\hline Construction & $1.83 * 10^{6}$ & $2.18 * 10^{6}$ & $1.67 * 10^{6}$ & $1.39 * 10^{6}$ & $1.59 * 10^{6}$ \\
\hline Maintenance & $0.77 * 10^{6}$ & $0.92 * 10^{6}$ & $0.70 * 10^{6}$ & $0.59 * 10^{6}$ & $0.66^{*} 10^{6}$ \\
\hline Operation & $0.13 * 10^{6}$ & $0.15 * 10^{6}$ & $0.05 * 10^{6}$ & 0 & 0 \\
\hline Total & $2.73 * 10^{6}$ & $3.25 * 10^{6}$ & $2.42 * 10^{6}$ & $1.98 * 10^{6}$ & $2.25 * 10^{6}$ \\
\hline
\end{tabular}

on had only one pumping station located at node number 9 , while the solution of Haghighi (2013) and that of the proposed ACOA-TGA-NLP is a gravity network with no pumping station.

It is worth noting that out of ten solutions produced by the proposed method, seven solutions have lower costs than the best solution of Li and Matthew (1990) and two solutions are cheaper than the best solution of Haghighi (2013) emphasizing on the superiority of the proposed method. Figure S1 shows the tree-like layout, pipe diameters and pump locations and heights for the six near optimal solutions obtained by the proposed ACOA-TGA-NLP method for the first text example locations and heights for the six near optimal solutions obtained by the proposed ACOA-TGA-NLP method for the first test example.

\section{Conclusions}

In this paper, two hybrid ACOA based methods, named ACOA-NLP and ACOA-TGA-NLP, were proposed for the efficient layout and pipe size determinations of pumped/ gravitational sewer network. In the first method, the ACOA was used for pipe diameters determination while an ad-hoc engineering based method was used for the layout determination. In the second method, the ACOA equipped with TGA was used for simultaneous layout and pipe diameter determinations in which the TGA was used to construct tree-like layouts. In both methods, the NLP method was used to optimally determine the pipe slopes of the sewer network with predefined pipe diameters and layout. The sewer flow velocity and relative flow depth constraints were expressed in terms of the slope constraints which were easily enforced as box constraint of the NLP solver leading to a considerable reduction of the search space size. Once the layout, pipe diameters and slopes were determined for a trial solution, the assumption of minimum cover depth at inlets of the network was used to calculate sewer pipes cover depths and the pump and drop heights of the network. In summary, the merits of the proposed method are twofold. First, this method can be used for optimal design of both pumped and gravitational sewer networks. Second, the computational effort required by the method is significantly reduced in comparison with alternative methods. Proposed methods were used to solve a benchmark test example and a hypothetical test example and the results were presented and compared with the available results. The results indicated the ability of the proposed methods and in particular the ACOA-TGA-NLP to optimally solve the problem of layout and size determination of pumped/gravitational sewer networks. It should be noted that these methods were proposed here for sewer networks with outlets of fixed positions. Further research is underway to extend the method for optimisation of sewer network outlets in addition to pipe size and layout optimization of the sewer network.

\section{References}

Afshar, M.H. (2007). Partially constrained ant colony optimization algorithm for the solution of constrained optimization problems: Application to storm water network design. Adv. Water Resour., 30(4), 954-965. http://dx.doi.org/10.1016/j.advwatres. 2006.08.004

Afshar, M.H. (2010). A parameter free Continuous Ant Colony Optimization Algorithm for the optimal design of storm sewer networks: Constrained and unconstrained approach. Adv. Eng. Software, 41(2), 188-195. http://dx.doi.org/10.1016/j.advengsoft.2009. 09.009

Afshar, M.H., Afshar, A., Marino, M.A., and Darbandi, A.A.S. (2006). Hydrograph-based storm sewer design optimization by genetic algorithm. Can. J. Civ. Eng., 33(3), 310-325. http://dx.doi.org/10. 1139/105-121

Afshar, M.H., Shahidi, M., Rohania, M., and Sargolzaei, M. (2011). Application of cellular automata to sewer network optimization problems. Sci. Iran. Trans. A: Civil Eng., 18(3), 304-312. http://dx. doi.org/10.1016/j.scient.2011.05.037

Argaman, Y., Shamir, U., and Spivak, E. (1973). Design of Optimal Sewerage Systems. J. Environ. Eng. Div., 99(5), 703-716.

Botrous, A., El-Hattab, I., and Dahab, M. (2000). Design of wastewater collection networks using dynamic programming optimization technique. In Proceeding Of the ASCE National Conference on Environmental and pipeline Engineering, Kansas City, MO, United States, American Society of Civil Engineers, 503-512.

Charalambous, C. and Elimam, A.A. (1990). Heuristic design of sewer networks. J. Environ. Eng., 116(6), 1181-1199. http://dx.doi. org/10.1061/(ASCE)0733-9372(1990)116:6(1181)

Dajani, J.S. and Hasit, Y. (1974). Capital cost minimization of drainage networks. J. Environ. Eng. Div., 100(2), 325-337.

Desher, D.P. and Davis, P.K. (1986). Designing sanitary sewers with microcomputers. J. Environ. Eng., 112(6), 993-1007. http://dx.doi. org/10.1061/(ASCE)0733-9372(1986)112:6(993)

Diogo, A.F. and Graveto, V.M. (2006). Optimal Layout of Sewer Systems: A Deterministic versus a Stochastic Model. J. Hydraul. Eng., 132(9), 927-943. http://dx.doi.org/10.1061/(ASCE)0733-9429(20 06)132:9(927)

Elimam, A.A., Charalambous, C., and Ghobrial, F.H. (1989). Optimum design of large sewer networks. J. Environ. Eng., 115(6), 1171-89. http://dx.doi.org/10.1061/(ASCE)0733-9372(1989)115:6 (1171)

Guo, Y. (2005). Sewer Network Optimal Design Based on Cellular 
Automata Principles. In Proceeding of 2005 XXXI IAHR Congress, Seoul, Korea, 6582-6593.

Guo, Y., Walters, G., and Savic, D. (2008). Optimal design of storm sewer networks: Past, Present and Future. In Proceeding of 11th International Conference on Urban Drainage, Edinburgh, Scotland, UK, 1-10.

Guo, Y., Walters, G.A., Khu, S.T., and Keedwell, E.C. (2006). Optimal Design of Sewer Networks using hybrid cellular automata and genetic algorithm. In Proceeding of IWA World Water Congress, Beijing, China.

Guo, Y., Keedwell, E.C., Walters, G.A., and Khu, S.T. (2007a). Hybridizing cellular automata principles and NSGA for multi-objective design of urban water networks. In Proceeding 4th international conference on Evolutionary multi-criterion optimization, 546-559, Springer Berlin Heidelberg. http://dx.doi.org/10.1007/ 978-3-540-70928-2 42

Guo, Y., Walters, G.A., Khu, S.T., and Keedwell, E.C. (2007b). A novel cellular automata based approach to storm sewer design. $J$. Eng. Optimiz., 39(3), 345-364. http://dx.doi.org/10.1080/03052150 601128261

Gupta, A., Mehndiratta, S.L., and Khanna, P. (1983). Gravity Waste Water Collection Systems Optimization. J. Environ. Eng., 109(5), 1195-1208. http://dx.doi.org/10.1061/(ASCE)0733-9372(1983)10 9:5(1195)

Heastad, M., Walski, M.T., Barnard, E.T., et al. (2004). Wastewater collection system modeling and design. Heastad Press, Waterbury CT.

Haghighi, A. (2013). Loop by loop cutting algorithm to generate layouts for urban drainage systems. J. Water Resour. Plann. Manage., 139(6), 693-703. http://dx.doi.org/10.1061/(ASCE)WR.1943-54 52.0000294

Haghighi, A. and Bakhshipour, A.E. (2012). Optimization of sewer networks using an adaptive genetic algorithm. Water Res. Manage., 26(12), 3441-3456. http://dx.doi.org/10.1007/s1 1269-012-0084-3

Haghighi, A. and Bakhshipour, A. (2015). Deterministic integrated optimization model for sewage collection networks using Tabu Search. J. Water Resour. Plann. Manage., 141(1), 0401-4045. http: //dx.doi.org/10.1061/(ASCE)WR.1943-5452.00004 35

Heaney, J.P., Wright, L.T., Sample, D., Field, R., and Fan, C.Y. (1999). Innovative methods for the optimization of gravity storm sewer design. In Proceedings the 8th international conference on urban storm drainage, Sydney, Australia, 1896-903.

Izquierdo, J., Montalvo, I., Perez, R., and Fuertes, V.S. (2008). Design optimization of wastewater collection networks by PSO. Comput. Math. Appl., 56(3), 777-784. http://dx.doi.org/10.1016/j. camwa.2008.02.007

Jang, S.H. (2006). Urban Storm Sewer Optimal Layout Design Model by DDDP Technique. In Proceedings 2006 Asia Oceania Geosciences Society, AOGS 2006, Singapore.

Karovic, O. and Mays, L.W. (2014). Sewer System Design Using Simulated Annealing in Excel. Water Res. Manage., 28(13), 45514565. http://dx.doi.org/10.1007/s11269-014-0750-8

Kulkarni, V.S. and Khanna, P. (1985). Pumped wastewater collection systems optimization. J. Environ. Eng., 111(5), 589-601. http: //dx.doi.org/10.1061/(ASCE)0733-9372(1985)111:5(589)

Li, G. and Matthew, R.G.S. (1990). New approaches for optimization of urban drainage system. J. Environ. Eng., 116(5), 927-944. http://dx.doi.org/10.1061/(ASCE)0733-9372(1990)1 16:5(927)
Liang, L.Y., Thompson, R.G., and Young, D.M. (2004). Optimising the design of sewer networks using genetic algorithms and tabu search. Eng Constr Architect Manage., 11(2), 101-112. http://dx. doi.org/10.1108/09699980410527849

Mays, L.W. and Wenzel, H.G. (1976). Optimal Design of Multi-level Branching Sewer Systems. Water Resour. Res., 12(5), 913-917. http://dx.doi.org/10.1029/WR012i005p00913

Miles, S.W. and Heaney, J.P. (1988). Better than "optimal" method for designing drainage systems. J. Water Resour. Plann. Manage., 114(5), 477-499. http://dx.doi.org/10.1061/(ASCE)0733-9496(19 88) $114: 5(477)$

Moeini, R. and Afshar, M.H. (2012). Layout and size optimization of Sanitary Sewer network using intelligent ants. Adv. Eng. Software, 51, 49-62. http://dx.doi.org/10.1016/j.advengsoft.20 12.05.003

Moeini, R. and Afshar, M.H. (2013). Constrained Ant Colony Optimization Algorithm for the layout and size optimization of sanitary sewer networks. Urban Water J., 10(3), 154-173. http://dx.doi.org /10.1080/1573062X.2012.716445

Moeini, R. (2013), Intelligent ant colony optimization algorithms for the solution of size-layout optimization problem: Application to water industry (sewer network), Ph.D. Thesis.

Moeini, R. and Afshar, M.H. (2017b). Arc Based Ant Colony Optimization Algorithm for optimal design of gravitational sewer networks. Ain Shams Eng. J. 8(2), 207-223. http://dx.doi.org/10.1016 /j.asej.2016.03.003

Pan, T.C. and Kao, J.J. (2009). GA-QP Model to Optimize Sewer System Design. J. Environ. Eng., 135(1), 17-24. http://dx.doi.org/ 10.1061/(ASCE)0733-9372(2009)135:1(17)

Price, R.K. (1978). Design of storm water sewers for minimum construction cost. In Proceeding of 1st International Conference on Urban Strom Drainage, Southampton, United Kingdom, 636-647.

Stutzle, T. and Hoos, H.H. (2000). MAX-MIN ant system. Future Gen. Comput. Systems, 16(8), 889-914. http://dx.doi.org/10.1016/ S0167-739X(00)00043-1

Sharma, A.K. and Swamee, P.K. (2008). Design method for circular and non-circular sewer sections. J. Hydraul. Res., 46 (1), 133-141. http://dx.doi.org/10.1080/00221686.2008.95218 49

Swamee, P.K. (2001). Design of Sewer Line. J. Environ. Eng., 127(9), 776-781. http://dx.doi.org/10.1061/(ASCE)0733-9372(2001)127: 9 (776)

Swamee, P.K. and Sharma, A.K. (2013). Optimal design of a sewer line using Linear Programming. Appl. Math. Model., 37(6), 44304439. http://dx.doi.org/10.1016/j.apm.2012.09.04 1

Swamee, P.K., Bhargava, R., and Sharma, A.K. (1987). Noncircular Sewer Design. J. Environ. Eng., 113(4), 824-833. http://dx.doi. org/10.1061/(ASCE)0733-9372(1987)113:4(824)

Templeman, A.B. and Walters, G.A. (1979). Optimal design of storm water drainage networks for roads. In Proceeding of Institution of Civil Engineers, Part 2, 6, 573-587.

Walsh, S. and Brown, L.C. (1973). Least cost method for sewer design. J. Environ. Eng. Div., 99(3), 333-345.

Walters, G.A. (1985). The design of the optimal layout for a sewer network. Eng. Optimiz., 9(1), 37-50. http://dx.doi.org/10.1080/030 52158508902500

Yen, B.C., Cheng, S.T., Jun, B.H., Voohees, M.L., and Wenzel, H.G. (1984). Illinois least cost sewer system design model, User's guide. Dept. of Civil Engineering, University of Texas at Austin 